How often should you open the door? Optimal monitoring to screen heterogeneous agents

Andrea Ichino

Gerd Muehlheusser

03-19

December 2003

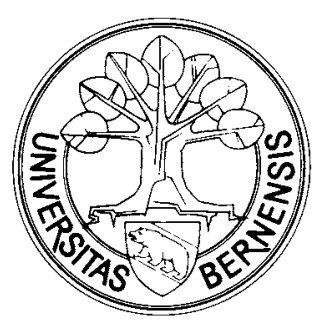

Universität Bern

Volkswirtschaftliches Institut

Gesellschaftstrasse 49

3012 Bern, Switzerland

Tel: 41 (0)316314506

Web: www.vwi.unibe.ch 


\title{
How often should you open the door?
}

\section{Optimal monitoring to screen heterogeneous agents}

\author{
Andrea Ichino* \\ Gerd Muehlheusser $^{\dagger}$ \\ EUI, CEPR, CESifo, IZA University of Bern and IZA
}

December 18, 2003

\begin{abstract}
This paper shows that monitoring too much a partner in the initial phase of a relationship may not be optimal if the goal is to determine his loyalty to the match and if the cost of ending the relationship increases over time. The intuition is simple: by monitoring too much we learn less on how the partner will behave when he is not monitored. Only by giving to the partner the possibility to mis-behave he might be tempted to do it, and only in this case there is a chance to learn his type at a time where separation would be possible at a relatively low cost.
\end{abstract}

JEL-Code: D2, D8, M5

Keywords: Monitoring, probation, effort, asymmetric information

*European University Institute, Department of Economics, Villa San Paolo, Via della Piazzola 43, 50133 Firenze, Italy. andrea.ichino@iue.it

${ }^{\dagger}$ Department of Economics, Gesellschaftsstrasse 49, 3012 Bern, Switzerland. gerd.muehlheusser@vwi.unibe.ch

We are very grateful to Elena Argentesi, Heski Bar-Isaac, Pascal Courty, Winand Emons, Eberhard Feess, Simon Lörtscher, Margaret Meyer, Massimo Motta, Andreas Roider, Karl Schlag, Klaus Schmidt, Eyal Winter and seminar participants at IZA and EUI, for helpful comments and discussions. The second author gratefully acknowledges financial support from the Department of Economics at the European University Institute through a Jean Monnet Fellowship. 


\section{Introduction}

The need to test the reliability of potential partners at the beginning of a project is a typical feature of many human relationships, not only of an economic nature. This need is particularly strong in the frequent cases in which, once the project starts, a separation from unreliable partners becomes more difficult. It is therefore not surprising that many partnerships feature, either explicitly or implicitly, an initial period of "probation" in which the persons involved monitor each other and decide, before it is "too late", whether to go on with the relationship or not. What is perhaps more surprising is that monitoring partners permanently during these probation periods may not be optimal, and in this paper we want to show why.

The intuition is simple. Consider an engagement before marriage in which the woman wants to test the loyalty of the potential husband (or vice versa if you prefer). A simplification not too far from reality is to assume that there are two types of men: those who will never betray their partner and those who instead might fall to the temptation of a love affair if an attractive occasion materializes. In order to find out to which type of men the potential husband belongs, the fiancee might try to spend as much time as possible with him, monitoring him closely in all his daily and night activities. In this way she would apparently learn a lot about him, but effectively she would not learn the most important thing to be learned, which is how the potential husband behaves when, as during marriage, he is not monitored

continuously. Only by giving the partner the possibility to mis-behave he might be tempted to do it, and only in this case his type could possibly be revealed when separating would still be feasible at low cost.

A similar situation characterizes labor market contracts where probation- 
ary periods are often specified explicitly. Note that the distinctive feature of these periods is not to make monitoring possible, but to be periods in which firing is allowed at a relatively low cost. Even when probation is not explicitly foreseen in a contract, various reasons (e.g. sunk costs or investments in job specific human capital) make it easier to fire a worker earlier in a career rather than later. In all these cases we argue that too much monitoring at the beginning of the relationship is not optimal, because it prevents the firm from learning how the worker behaves when she is not monitored. As in the case of the engagement before marriage, the firm is typically interested in discriminating between two types of potential employees: those who are "unconditional cooperators", and therefore exert a maximum level of effort in all instances, and those who are instead "rational shirkers", and would therefore indulge in laziness if the cost of effort is high and the probability of detection sufficiently low. Inasmuch as the "rational shirkers" can mimic the behavior of the "unconditional cooperators" during probation, continuous monitoring ("keeping the office door always open") is suboptimal because the probability of detection would be too high and the "rational shirker" would never concede to the temptation of being "lazy". As a result the two types of workers would be observationally identical during probation, and only when firing becomes costly would the true types be revealed. On the contrary, random monitoring ("opening the door not too often and with no specific pattern") might be more revealing because the "rational shirker" would be induced to take a chance to be lazy. Thus, only in this case would there be a chance that the two types of workers might be caught behaving differently.

Also in the case of trading between firms, and in general between "buyers" and "sellers", the same type of result might apply. Most firms write 
long-term contracts with other firms to obtain inputs for their production process. The selection of partners for the provision of inputs may be subject to a trial period similar to the one that characterizes labor or marriage contracts. What this paper suggests is that these periods would be totally uninformative about the reliability of the trading partners if the buyer announced his willingness to monitor extensively the quality of the input acquired during trial. If the unreliable sellers knew that they would be fully monitored during trial, they would try to make their product indistinguishable from the product of reliable sellers. However, this would offer no guarantee that the product would be of high quality after the long-term contract is signed.

Note that our argument does not apply only to long-term relationships but is also relevant for one-shot interactions in which the reliability of a partner is so important that it becomes crucial to test it before the main interaction starts. Thus, our intuition is in principle relevant for many kinds of human relationships, but of course not for all of them. Therefore, in the light of the above examples and before going into a formal description of our model in Section 3, it may be useful to clarify, within a generic "principalagent" framework, what is needed for our intuition to apply. We will do this in the next section at the end of which it will be evident that the set of relevant cases is quite large.

\section{The necessary ingredients}

First, there must be heterogeneity of agents with respect to the cost of exerting effort, an hypothesis which probably characterizes most human relationships and which is for example strongly supported by the evidence described in Nagin, Rebitzer, Sanders, and Taylor (2002) and Ichino and Riphahn 
(2003)! Without loss of generality, we distinguish between "good" agents who are willing to exert effort unconditionally and "bad" agents who instead face effort costs and therefore are potential shirkers. Since a shirking agent yields a negative payoff to the principal, the latter is interested in identifying bad agents in order to stop the relationship with them.

Second, splitting from an agent must become more costly for the principal as the length of the relationship increases. Although this assumption restricts somewhat the set of relevant cases, it captures a feature that often characterizes long-term relationships. This feature is sometimes a consequence of institutional arrangements, like engagements in the marriage market and probation periods in the labor market, but the existence of such an explicit reference to a trial period is not necessary for our story. Splitting may become increasingly difficult also because of sunk costs paid at some point during the relationship or because of the accumulation of match-specific capital that would be too costly to destroy in case of splitting up. For any of the above reasons, the principal is interested in identifying bad agents as early as possible, in order not to remain stuck with them when firing becomes too expensive. On the other hand, for the same reasons, bad agents have an extremely strong incentive to mimic good agents, because when firing becomes too costly for the principal they can shirk at no risk. ${ }^{2}$

\footnotetext{
${ }^{1}$ The first paper analyzes data from a field experiment in which the monitoring rate is varied to see how people react to it in terms of shirking. It finds that, although there are many "rational shirkers", a significant proportion of agents does not take advantage when the monitoring rate goes down and can thus be classified as "unconditional cooperators". The second one compares the absenteeism rate of newly hired workers during and after probation in a large Italian bank. $42 \%$ of them are never absent while among the others an increase in absenteeism is observed on average when incentives change at the end of probation.

${ }^{2}$ The principal's attempt to find out an agent's type induces bad agents to try to mimic good types which makes both types to appear more similar. This feature is reminiscent to models of reputation games á la Kreps, Milgrom, Roberts, and Wilson (1982) and Fudenberg and Levine (1992). On the other hand, in Mailath and Samuelson (2001), it is
} 
Third, we consider only situations in which it is either impossible or too costly to design menus of contracts capable of "screening" between the two types of workers. Once again, this should not appear as a particularly restrictive assumption, since in any realistic setup, the number of different contracts which can be offered by a principal is "finite", so that there might still exist some degree of heterogeneity among agents who choose a particular contract. In the extreme case frequently encountered in real-world labor markets, there are institutional constraints such that workers who do the same job must also get the same (fixed) wage. This is the case we consider but our results do not qualitatively change as long as the type space is "richer" than the space of potential contracts to offer so that there is heterogeneity for each different type of contract. Moreover, our setting implies that bad types have a strong incentive to mimic good types, since they would otherwise be fired when choosing the contract designed for them. Thus, such screening contracts either do not exist, or even if they do, it would be relatively expensive for the principal to use them because of the significant rents to be offered to agents to satisfy the incentive and the participation constraints. After all, the fact that probation periods exist in many long-term relationships of different nature indicates that it is not so easy to define menus of contracts capable of implementing an efficient screening of workers.

Fourth, the monitoring of agents must be possible and thus constitute a feasible means to identify bad agents. When using the monitoring device, the principal can observe the effort decision of an agent in such a way that

a good type who can take an action to distinguish himself from a bad (inept) type. Avery and Meyer (2003) analyze a model in which both types of agents may act strategically. They show that it is possible to have two kinds of equilibria: one in which the two types appear more similar in which case the degree of informativeness for the principal is relatively low, and one in which they appear more distinct from each other so that the degree of informativeness is larger. 
the effort choice becomes in fact "observable" although it remains "nonverifiable" in court. Thus a contract cannot condition on it. However, during the probation period, splitting is possible (or has lower cost) precisely in the sense that there is no need to verify misbehavior in court in order to end the relationship.

Whenever these four conditions are met, the principal faces a trade off when deciding on the optimal monitoring policy for the probation period. On the one hand, with zero monitoring the principal would have no chance of detecting a bad agent and thus some monitoring is beneficial for the principal. On the other hand, there is a countervailing effect since monitoring induces bad types to exert effort in the probation period, thereby preventing their identification.

As explained above, our main result is that even if monitoring is costless, there is an incentive to choose a relatively small monitoring frequency in order to induce some of the bad types to shirk in the probation period. Note that the mere objective of filtering out bad agents is sufficient to generate this result, and assuming monitoring to be costless makes our point particularly striking, as, with monitoring costs, the optimal monitoring rate would be even lower. Thus, our result is qualitatively different from the literature on law enforcement building on Becker (1968) in which the fact that optimal detection probabilities are typically less than one is driven by the presence of enforcement costs (see also Besanko and Spulber (1989) and Polinsky and Shavell (2000)).

In the Personnel Economics literature, probation is often rationalized as an institution aimed at screening workers in the presence of unobservable worker productivity (see e.g. Guasch and Weiss (1981), Sadanand, Sadanand, and Marks (1989), and Bull and Tedeschi (1989)), but we are not aware of a 
literature signaling the existence of the above-mentioned trade-off and studying its implications. The paper by Wang and Weiss (1998) is, to some extent, related to the point we want to make. They analyze in a more general setting the possibility of using random tests to screen workers during probation, in combination with wage schedules which differ according to the outcome of the test. By highlighting this combination of tools, they show that "excessive monitoring" can deter low productivity workers from applying for jobs, thereby making the pool of applicants endogenous. Independently from their intuition, however, our story would apply whenever there is some residual heterogeneity, e.g. concerning the propensity towards shirking, after agents have been hired. Note that the two stories together suggest the possibility that the firm's ex ante commitment to excessive monitoring in order to deter bad applicants may be time-inconsistent when the screening process is not perfect and the firm hires bad workers in equilibrium..$^{3}$

Our analysis is also related to Cowen and Glazer (1996) and Dubey and $\mathrm{Wu}(2001)$ who show that a principal might benefit from having a less accurate picture of agents. In the first paper, in trying to exceed a given threshold, an agent might exert more effort when he is monitored with low frequency only. This is because the risk of not exceeding the threshold is higher when he has "fewer chances" and this may increase his effort incentives. In the second paper, the principal wants to induce maximum effort by all agents. Agents have different skills and are monitored at random. The agent with the highest observed output receives a prize. To also give the low ability agents a chance to win the prize, the principal might have an interest in keeping the

\footnotetext{
${ }^{3}$ The importance of commitment power is also stressed in the literature on law enforcement and auditing where the problem of time inconsistency is also prevalent (see e.g. Kaplow and Shavell (1994)). See Khalil (1997) for a model in which the principal cannot commit in advance to a monitoring rate.
} 
sample of observations small (i.e. to monitor less often) since large samples would tend to favor high ability agents as they are more likely to produce a high output. In both papers, less monitoring may lead to more effort and may therefore be preferred by the principal. Contrary to that, in our paper, less monitoring leads to more shirking and this is beneficial for the principal because it allows to screen the different types of agents. Moreover, the result in the second paper is driven by the competition among agents for the prize, while our argument does not rely on interaction among agents.

The rest of this paper is devoted to analyzing formally what we have so far described intuitively.

\section{The Model}

We consider one principal facing $N \geq 1$ agents in a relationship lasting at most two periods $i=1,2$. Period 1 is a probation period while period 2 is the time after probation. In each period, agents can choose an action from $\{E, S\}$ where $E$ and $S$ denote "exerting effort" and "shirking", respectively. A shirking agent produces 0 output, while, when exerting effort, each agent produces $v_{i}$ in period $i$. We have in mind situations in which the output of an agent's effort in period 1 is negligible compared to period 2, and thus we assume $v_{1}=0$ and $v_{2}>0 .\left[4\right.$ We interpret $v_{2}$ as a Net Present Value thereby allowing period 2 to be of any length relative to the probation period. In particular, period 2 could last for some time so that $v_{2}$ would reflect the overall discounted output in a long-term relationship, or period 2 could be short indicating, for example, that the principal benefits from the effort of the agent only at a single (but maybe particularly important) occasion.

\footnotetext{
${ }^{4}$ To assume $v_{1}=0$ allows us to better highlight our basic result but this neither affects its validity nor its generality. We will briefly comment on the case $v_{1}>0$ in section 4 .
} 
Although all agents are equally valuable to the principal when exerting effort, they differ with respect to the (privately known) cost of doing so which is represented by a parameter $\theta \in\{G, B\}$ : "bad types", denoted by $\mathrm{B}$, have effort costs $c_{i}$ in period $i$, where $c_{1}=c, c_{2}=k \cdot c$ with $k>0$, and where $c$ is drawn from a distribution $H(c) \in C^{2}$ with support $[0,1]$ at the beginning of the game. The parameter $k$ is simply a proportionality factor which allows for appropriately adjusting and discounting effort costs with respect to the length of period 2 relative to period 1 . Furthermore, $k$ can also be thought to reflect potential differences in the intensity of effort required during and after probation. On the other hand "good types", denoted by $G$, do not face any costs of exerting effort. ${ }^{[5}$ In the population of agents, the shares of good and bad types are $\alpha$ and $(1-\alpha)$, respectively, where $0<\alpha<1$. Concerning the informational environment, we assume that each agent privately learns his type at the beginning of the game and that $\alpha$ and $H(\cdot)$ are common knowledge.

Period 1 is a probation period in which the principal can monitor each agent at no cost. His choice variable is thus a probability of monitoring $q \in$ $[0,1]$. The outcome of the monitoring process is captured by a variable $M \in$ $\{E, S\}$ which perfectly reveals when shirking has occurred. After observing the outcome of the monitoring process and updating his beliefs appropriately by use of Bayes' rule, the principal makes a firing decision $F \in\{0,1\}$, where $F=1$ means that an agent is fired. Firing costs in the trial period are zero, while in the second period they are prohibitively high. ${ }^{6}$ It is assumed that

\footnotetext{
${ }^{5}$ As explained in the Introduction, this view is for example broadly confirmed in a field experiment reported in Nagin, Rebitzer, Sanders, and Taylor (2002). Alternatively, we could assume that good types face effort costs which are lower on average than those of bad types. This would not change our arguments qualitatively.

${ }^{6}$ Once again, the qualitative nature of our results would not change if firing costs after probation were high but finite.
} 
the population out of which the $N$ agents are drawn is sufficiently large such that, upon monitoring one agent, no inference can be made about the pool composition of the remaining $N-1$ agents.

As for payments, we denote by $t_{i}$ the transfer from the principal to each agent. During probation, the transfer $t_{1}$ could in principle be set equal to zero, although in most situations it would be natural to imagine that some kind of "show-up fee" $t_{1}>0$ is paid to the worker independently of the probation outcome. In the case of period 2, if the worker is hired at the end of probation, he cannot be fired later in the sense that he is in any case entitled to a transfer $t_{2}>t_{1}$ independently of his performance. We also make the following assumption:

Assumption 1. $v_{2}>t_{2}>1$

which implies that the payoff for the principal from each agent who exerts effort in period 2 is positive $\left(v_{2}>t_{2}\right)$. Furthermore, as explained below, $t_{2}>1$ implies that in period 1, exerting effort is privately optimal for a bad agent for any value of $c$ when he is monitored with certainty.

Given Assumption 1, and coming back to the firing decision, we want the principal to wish to continue with an agent when his belief after the monitoring process is greater or equal to the prior $\alpha !^{7}$ This will imply that the following assumption must hold:

Assumption 2. $\alpha \cdot\left(v_{2}-t_{2}\right)+(1-\alpha) \cdot\left(-t_{2}\right)>0$

Summarizing, the game has the following stages:

- At stage 0, each agent's type is determined by a nature's move and is only known to the agent.

\footnotetext{
${ }^{7}$ We can alternatively assume that an agent cannot be fired without being monitored. This would for example be consistent with legal practice in the US, see Krueger (1991).
} 
- At stage 1 , the principal sets and commits to a monitoring probability $q$ for the probation period.

- At stage 2 period 1 begins and each agent independently decides on whether or not to exert effort. After the effort choice is made, each agent is monitored with probability $q$.

- At stage 3, given the outcome of the monitoring procedure, the principal decides on which agents to fire. After the firing decision period 1 ends.

- At stage 4 , in period 2, all remaining agents again decide on whether or not to exert effort. Then the game ends.

\subsection{Equilibrium Behavior of the Agents}

Let us start the analysis of the game at stage 4 , and denote by $a_{i}^{\theta} \in\{E, S\}$ the action chosen by type $\theta \in\{B, G\}$ in period $i=1,2$. Equilibrium values carry an asterisk * We start with a good type: Since he has no effort costs, he is indifferent between exerting effort and shirking (both actions yield a payoff of $t_{2}$ ). Throughout we assume that both types exert effort when indifferent, so that good types will always choose $a_{2}^{G *}=E$ in period $2 .^{8}$ Contrary to that, in period 2, a bad type gets $\left(t_{2}-k \cdot c\right)$ from choosing $E$ and $t_{2}$ from choosing $S$ so that bad types will always shirk in period 2, i.e. $a_{2}^{B *}(c) \equiv S \forall c>0$.

Let us now look at the principal's optimal firing decision at stage 3 after monitoring has been carried out. Denote by $\beta \in[0,1]$ the belief of facing a good type conditional on the outcome of the monitoring process:

$$
\beta:=\operatorname{Pr}(\theta=G \mid M)
$$

\footnotetext{
${ }^{8}$ All we need is that the expected payoff for the principal in period 2 from having a good (bad) type is positive (negative).
} 
Of course, in (a Bayesian perfect) equilibrium, whenever possible, this has to be consistently derived using Bayes' rule from the equilibrium strategies of each type of agent at stage 2 (see e.g. Fudenberg and Tirole (1991)). Given that good types will exert effort while bad types will always shirk in period 2 , the principal's expected payoff from an agent for period 2 as a function of $\beta$ is given by

$$
\beta\left(v_{2}-t_{2}\right)+(1-\beta)\left(-t_{2}\right)
$$

which may be positive or negative. It follows that the principal will fire an agent, whenever monitoring "delivers" a belief for this agent to be a good type which is sufficiently low:

$$
F^{*}(\beta)=\left\{\begin{array}{cc}
1 & \text { if } \beta<\frac{t_{2}}{v_{2}} \\
0 & \text { otherwise }
\end{array} .\right.
$$

Now consider the optimal effort decision at stage 2 by each type for a given probability of monitoring $q$. In doing so, we directly look at the following equilibrium continuation and then see how it can be supported:

Lemma 1. At stage 2, for all $q<\bar{q}:=\frac{1}{t_{2}}$, there exists a unique equilibrium continuation in which

a) each good type chooses $a_{1}^{G *}=E$ independent of $q$,

b) each bad types shirks whenever his realization of $c$ is sufficiently high. This happens with probability $(1-e(q))>0, \frac{9}{9}$

c) the principal's beliefs after monitoring has been carried out are given by

$$
\begin{array}{r}
\beta^{*}=\operatorname{Pr}(\theta=G \mid M=E)=\frac{\alpha}{\alpha+(1-\alpha) e(q)}>\alpha \\
\beta^{*}=\operatorname{Pr}(\theta=G \mid M=S)=0
\end{array}
$$

and the principal optimally fires all agents for whom $M=S$ holds and thus keeps all other agents (including those who have not been monitored).

\footnotetext{
${ }^{9}$ The exact definition of $e(q)$ is given in Eqn. 9 below.
} 
For an intuition for Lemma 1, let us start with a good type: On the equilibrium path, when choosing $E$, he gets $t_{1}$ in period 1 , and $t_{2}$ in period 2 : if he is monitored, this will lead to $M=E$ and so the principal holds the belief $\beta^{*}=\frac{\alpha}{\alpha+(1-\alpha) e(q)}>\alpha$ for which, by Assumption $2, F=0$ is optimal. If he is not monitored, the principal holds belief $\beta^{*}=\alpha$ and he is not fired either. On the other hand, when choosing $S$ in the first period, his payoff is still $t_{1}$ since he does not save in effort costs. But with probability $q$, he is monitored, found to be shirking and, given belief $\beta^{*}=\operatorname{Pr}(\theta=G \mid M=S)=0$, fired. It follows that his expected payoff for period 2 is only $(1-q) t_{2}$ and, thus, a deviation is never profitable.

Now consider a bad type: When choosing $E$, he gets $\left(t_{1}-c\right)$ in period 1. When monitoring occurs, he is taken to be a good type and thus will also get $t_{2}$ in period 2 in which he will then shirk, so that he will not again incur any cost of effort in that period. On the other hand, when choosing $S$, he gets $t_{1}$ in period 1 (thus saving on effort costs $c$ ), but with probability $q$ he is found to be shirking and fired, so that his expected payoff for period 2 is only $(1-q) t_{2}$. It follows that $S$ is preferred iff

$$
t_{1}-c+t_{2}<t_{1}+(1-q) t_{2} \Leftrightarrow c>q t_{2}
$$

so that the optimal decision of a bad type as a function of $q$ and $c$ is given by

$$
a_{1}^{B *}(q, c)= \begin{cases}S & \text { if } c>q t_{2} \\ E & \text { otherwise }\end{cases}
$$

i.e. shirking occurs whenever effort costs are sufficiently high. This means that for $q \geq \bar{q}:=\frac{1}{t_{2}}$, all bad types choose $E$ independent of their cost parameter $c$. The threshold $\bar{q}$ relates the benefit from employment in period $2\left(t_{2}\right)$ to the maximum cost of effort during probation which is equal to 1. Clearly, when $t_{2}$ is relatively large, then $\bar{q}$ is low, which means that shirking 
in period 1 is undesirable for a bad agent given the prize at stake. Thus, even a relatively low level of $q$ would induce all bad agents to exert effort as long as $q$ is set greater or equal than $\bar{q}$. In this case, shirking would no longer occur on the equilibrium path so that there would be no information transmission in equilibrium and $\beta^{*}=\operatorname{Pr}(\theta=G \mid M=E)=\alpha$ would hold. This in turn would allow for a plethora of pooling equilibria, since Bayes' rule would have no bite in case of $M=S$ because this is then a zero probability event. However, we will show below that it is indeed optimal for the principal to choose some $q<\bar{q}$ so that both possible actions, $E$ and $S$, occur with positive probability on the equilibrium path. Therefore, there is no leeway in forming off-equilibrium beliefs and so this equilibrium continuation is indeed unique. 10 Finally, note that the principal's beliefs conditional on $M$ are consistent with the equilibrium strategies of both types.

\subsection{The Principal's Optimal Choice of $q$}

It remains to be determined the optimal choice of $q$ at stage 1 , under the assumption that the equilibrium continuation as derived in Lemma 1 is played subsequently. Clearly, the principal's objective is to maximize her expected payoff. Let us analyze each part of it in turn:

Good Types: In period 1 , there are $\alpha \cdot N$ good types, none of them shirks in equilibrium and therefore none of them is fired. Since for simplicity we assumed a negligible output during probation, they yield a negative payoff $\left(-t_{1}\right)$ to the principal, but the important point is that this payoff is independent of the monitoring probability $q$. In period 2 , there is again no shirking and each of the $\alpha \cdot N$ good types yields the principal $\left(v_{2}-t_{2}\right)>0$, which is again independent of $q$. This means that the choice of $q$ neither influences

\footnotetext{
${ }^{10} \mathrm{We}$ confine attention to pure strategy equilibria.
} 
the number of good types in each period nor their choice of effort. Therefore, in what follows, we can neglect the payoff accruing from good types as it will have no effect on the optimal level of $q$.

Bad Types: Recall that a bad type will shirk in period 1 whenever $c>q t_{2}$. Thus, from the principal's point of view, the probabilities of shirking and exerting effort are given by, respectively,

$$
\begin{aligned}
& s(q):=\operatorname{Pr}\left(c>q t_{2}\right)=\max \left(0,1-H\left(q t_{2}\right)\right) \\
& e(q):=\operatorname{Pr}\left(c \leq q t_{2}\right)=\min \left(H\left(q t_{2}\right), 1\right) .
\end{aligned}
$$

Clearly we have $\frac{d s}{d q} \leq 0$ and $\frac{d e}{d q} \geq 0$ and $s^{\prime}(q)=-e^{\prime}(q)$.

Since there are $(1-\alpha) \cdot N$ bad types, the expected payoff generated by them in period 1 is:

$$
\begin{aligned}
\pi_{1}(q) & :=(1-\alpha) \cdot N \cdot\left(e(q) \cdot\left(-t_{1}\right)+s(q) \cdot\left(-t_{1}\right)\right) \\
& \left.=(1-\alpha) \cdot N \cdot\left(-t_{1}\right)\right)
\end{aligned}
$$

because $e(q)+s(q)=1$. Note that this term is also independent of $q$. This highlights the fact that in period 1 the principal monitors workers not so much because she is interested in their output, which in this period is negligible, but mainly because she needs to detect bad workers.

In other words, from the principal's point of view, monitoring in period 1 matters only because it influences the number of bad types in period 2 . And precisely for this reason $q$ must be set in a way that induces some shirking in period 1, otherwise no bad type would be detectable. Formally, the number of bad types in period 2 is determined as follows: Each bad type shirks with probability $s(q)$ but gets detected only with probability $q$ so that $(1-\alpha) \cdot N \cdot(1-q) \cdot s(q)$ bad types remain in period 2. Moreover, each bad type exerts effort with probability $e(q)$ and is thus not identified through 
monitoring so that another $(1-\alpha) \cdot N \cdot e(q)$ of them survive the probation period. Taking this together, since each bad types generates a payoff of $\left(-t_{2}\right)$ to the principal, her expected payoff from the bad types in period 2 is given by

$$
\pi_{2}(q):=(1-\alpha) \cdot N \cdot((1-q) \cdot s(q)+e(q)) \cdot\left(-t_{2}\right)
$$

We can therefore state the following result concerning the optimal monitoring frequency $q^{*}$ :

Proposition 1. Given equilibrium continuation 1, the optimal monitoring frequency for the principal induces shirking on the equilibrium path, i.e. $0<$ $q^{*}<\bar{q}:=\frac{1}{t_{2}}<1$.

Proof. We proceed along the following lines: Since the objective function of the principal is continuous in the interval $[0, \bar{q})$,

i) we show that the expected payoff of the principal is strictly increasing at $q=0$ and strictly decreasing as $q \rightarrow \bar{q}$.

ii) we show that the absolute expected profit level is also higher at $q=q^{*}$ than at $q=0$ and when $q$ approaches $\bar{q}$ (the payoff function of the principal is flat for all $q \geq \bar{q}$ ).

To do this, define

$$
\begin{aligned}
Z(q) & :=[(1-q) s(q)+e(q)]\left(-t_{2}\right)=[(1-q)(1-e(q))+e(q)]\left(-t_{2}\right) \\
& =\left[(1-q+q e(q)]\left(-t_{2}\right)\right.
\end{aligned}
$$

where

$$
Z^{\prime}(q)=\left[-1+e(q)+q e^{\prime}(q)\right]\left(-t_{2}\right) .
$$

Recall that the expected payoff from the good agents and from the bad agents in period 1, respectively, is independent of $q$. Furthermore, from (11), $\pi_{2}(q)=(1-\alpha) \cdot N \cdot Z(q)$ so that $q^{*}$ is uniquely determined by $Z(q)$. 
ad i): We need to show that $Z^{\prime}(q=0)>0$ and $Z^{\prime}\left(q \rightarrow \frac{1}{t_{2}}\right)<0$ :

$$
\begin{aligned}
Z^{\prime}(q=0) & =t_{2}>0 \\
Z^{\prime}\left(q \rightarrow \frac{1}{t_{2}}\right) & =\left(-t_{2}\right) \cdot\left[-1+\frac{1}{t_{2}} \cdot e^{\prime}\left(\frac{1}{t_{2}}\right)+1\right]=-e^{\prime}\left(\frac{1}{t_{2}}\right)<0
\end{aligned}
$$

ad ii): Note that we have

$$
\begin{aligned}
Z(0) & =Z\left(\frac{1}{t_{2}}\right)=-t_{2} \\
Z\left(q^{*}\right) & =\left(1-e\left(q^{*}\right)+q^{*} \cdot e\left(q^{*}\right)\right)\left(-t_{2}\right)
\end{aligned}
$$

and thus

$$
\begin{aligned}
Z\left(q^{*}\right)-Z(0)>0 & \Leftrightarrow \\
\left(1-e\left(q^{*}\right)+q^{*} \cdot e\left(q^{*}\right)\right)\left(-t_{2}\right)>\left(-t_{2}\right) & \Leftrightarrow \\
e\left(q^{*}\right) & <1
\end{aligned}
$$

which is true for all $q^{*}<\bar{q}$. Thus, the principal's payoff is strictly higher when an interior level of $q$ is chosen.

Note first that $q^{*}<\bar{q}$ implies that the behavior determined in the equilibrium continuation (see Lemma 1) is also optimal and so Lemma 1 together with Proposition 1 characterize indeed the unique equilibrium of this game.

Intuitively when $q$ is too low, only few bad agents are identified while when $q$ is too high, each bad agent is less likely to shirk in period 1 and thus cannot be identified through monitoring either. As bad types shirk with probability 1 in period 2 (yielding a negative payoff $-t_{2}<0$ ), too much monitoring is not in the principal's interest. Note that this argument does not rely on monitoring costs which are assumed to be zero.

To give an account of the potential magnitude of the gain induced by setting $q$ optimally, we now calculate the percentage gain in profits for the 
principal from monitoring with probability $q=q^{*}$ compared to monitoring excessively $(q \rightarrow \bar{q})$ or refraining from monitoring at all $(q=0)$. Using Eqn. (11), we denote by $d(q)$ the probability that a bad type remains in period 2 , i.e.

$$
d(q):=(1-q) s(q)+e(q)=1-q \cdot s(q)
$$

which simply reflects the fact that a bad agent can only be fired if he shirks in period 1 and is detected through monitoring. Note that $d(q=0)=$ $1=d(q \geq \bar{q})$ which implies that all bad agents remain in period 2 and the principal's payoff in either of these two cases is

$$
\pi_{2}(q=0)=\pi_{2}(q \rightarrow \bar{q})=(1-\alpha) \cdot N \cdot\left(-t_{2}\right)
$$

When $q^{*}$ is chosen, instead, the probability that a bad type remains in period 2 is strictly less than 1 , i.e. $d\left(q^{*}\right)=1-q^{*} \cdot s\left(q^{*}\right)<1$. Thus, the principal is able to filter out at least some of the bad types so that her payoff is

$$
\pi_{2}\left(q=q^{*}\right)=(1-\alpha) \cdot N \cdot\left(1-q^{*} \cdot s\left(q^{*}\right)\right) \cdot\left(-t_{2}\right) .
$$

By taking the difference between (16) and (15), her absolute gain from choosing an "interior" monitoring frequency $q^{*}$ is:

$$
\begin{aligned}
\Delta \pi & :=\pi_{2}\left(q=q^{*}\right)-\pi_{2}(q=0) \\
& =(1-\alpha) \cdot N \cdot\left(-q^{*} \cdot s\left(q^{*}\right)\right) \cdot\left(-t_{2}\right)>0
\end{aligned}
$$

Relative to the payoff obtained in the "corner" solutions given by Eqn. (15), the percentage increase in profits can thus be calculated as

$$
\frac{\Delta \pi}{\left|\pi_{2}(q=0)\right|}=q^{*} \cdot s\left(q^{*}\right) .
$$

To further illustrate this result, consider the case where $c$ is uniformly distributed, i.e. $H(c)=c$. Using (9), we then have $e(q)=\min \left(q t_{2}, 1\right)$ and 
maximizing $\pi_{2}(q)$ in Eqn. (11) with respect to $q$ yields $q^{*}=\frac{1}{2 t_{2}}$ and thus $e\left(q^{*}\right)=s\left(q^{*}\right)=\frac{1}{2}$. Therefore, from Eqn. (18) the percentage gain is given by $\frac{1}{4 t_{2}}=\frac{1}{4} \bar{q} \cdot \underline{11}$

This example highlights a corollary implication of our model. Not only is it never optimal to monitor too much during probation, as suggested by Proposition 1, but, in addition, when $\bar{q}$ is low because the value of employment is high, probation is not a very effective device to filter out bad agents even if the monitoring probability is set optimally to $q^{*}<\bar{q}$. On the other hand, in the opposite case in which $\bar{q}$ is high, i.e. when the (maximum) cost of effort in period 1 is high compared to the benefit from employment in period 2, the principal can achieve considerable gains by having probation periods in which monitoring is used as a selection device. Even in this case, however, it would never be optimal to set the monitoring probability $q^{*}$ above $\bar{q}$.

\section{Conclusions and Extensions}

We have shown in this paper that monitoring a partner too much in the initial phase of a relationship may not be optimal if the goal is to determine her loyalty to the match and if the cost of terminating the relationship increases over time. If too much monitoring induces the partner to behave well even if her inclination in the absence of monitoring would be to mis-behave, the principal does not learn what needs to be learned at the beginning of a relationship. Note that this mechanism is completely independent of the

\footnotetext{
${ }^{11}$ It may be worth noting that our result also bears some analogy to the standard monopoly model and to the idea underlying the so-called Laffer-Curve. In the first case, compared to the competitive outcome, a monopolist can increase its profit by setting a higher price although total sales will be lower. In the second case, by setting a low tax rate a government is able to generate a higher tax income since this increases the tax base.
} 
costs of monitoring, and thus the result holds even if monitoring is costless. This general intuition applies to many social relationships characterized by asymmetric information with respect to the types of agents, like for example, labor and marriage contracts.

Our streamlined framework allows us to derive our basic result in its purest form at the cost of some simplifications. For example, the assumption of negligible output in the probation period or the assumption that the principal cannot set up an incentive scheme in period 2 to elicit some effort from bad types. Note however that removing these assumptions would complicate the analysis without changing the fundamental nature of the trade-off highlighted by our paper. For example, a positive $v_{1}$ would clearly increase the optimal monitoring probability $q^{*}$, but as long as output in period 2 is what really matters for the principal, our story would not change qualitatively. And even if it were possible to design an incentive scheme capable of eliciting effort from bad types in period 2, such a scheme would probably be costly and imperfect in reality, leaving the principal with the need to perform at least some screening during the initial phase of the relationship. Thus, even in a more general setting, the principal is interested in increasing the number of bad agents detected during probation.

As a corollary of our analysis we also show that the use of probation periods, together with monitoring during such periods, is beneficial to the principal only when agents perceive a benefit from future interaction which is not too large in comparison to the cost of exerting effort during probation. Only in these cases the optimal monitoring probability can be set high enough to allow for the detection of some bad agents and at the same times bad agents may be induced to shirk even during probation. On the contrary, when an agent's future benefit from the relationship is perceived to be too 
high, the probability of monitoring that would induce some shirking among bad types would have to be too low, and as a result very few bad types would be detected. In these cases, our model suggests that probation would be a waste of time as a method to detect bad agents through monitoring.

Although at this stage our paper has essentially a normative flavor, in terms of positive analysis it suggests that relationships in which too much monitoring takes place at the beginning should perform worse at later stages of their development. In particular, everything else being equal, a larger fraction of less loyal agents, or a higher probability of not loyal behavior from a single agent, should emerge in the long run when the principal monitors agents too much at the beginning. What comes next in our research agenda is to explore the possibility of providing empirical evidence on this testable prediction of our model. 


\section{References}

Avery, C., and M. Meyer (2003): "Designing Hiring and Firing Procedures When Evaluators are Biased," mimeo.

Becker, G. (1968): "Crime and Punishment: An Economic Approach," Journal of Political Economy, 76(2), 169-217.

Besanko, D., And D. F. Spulber (1989): "Antitrust Enforcement Under Asymmetric Information," Economic Journal, 99(396), 408-425.

Bull, C., and P. Tedeschi (1989): "Optimal Probation for New Hires," Journal of Institutional and Theoretical Economics, 145(4), 627-642.

Cowen, T., and A. Glazer (1996): "More monitoring induces less effort," Journal of Economics Behavior \&3 Organization, 30, 113-123.

Dubey, P., And C.-W. Wu (2001): "Competitive Prizes: When Less Scrutiny Induces More Effort," Journal of Mathematical Economics, 36, 311-336.

Fudenberg, D., And D. K. Levine (1992): "Maintaining a Reputation when Strategies are Imperfectly Observed," Review of Economic Studies, $59,561-579$.

Fudenberg, D., And J. Tirole (1991): Game Theory. MiT Press, Cambridge, Mass.

Guasch, J. L., And A. Weiss (1981): "Self-Selection in the Labor Market," American Economic Review, 71(3), 275-284. 
Ichino, A., And R. Riphahn (2003): "'The Effect of Employment Protection on Worker Effort - A Comparison of Absenteeism During and After Probation," mimeo.

Kaplow, L., and S. Shavell (1994): "Optimal Law Enforcement with Self-Reporting Behavior," Journal of Political Economy, 102(3), 583-606.

KhaliL, F. (1997): "Auditing Without Commitment," RAND Journal of Economics, 28(4), 629-640.

Kreps, D., P. Milgrom, J. Roberts, and R. B. Wilson (1982): "Rational Cooperation in the Finitely Repeated Prisoners' Dilemma," Journal of Economic Theory, 27, 245-252.

Krueger, A. B. (1991): "The Evolution of Unjust-Dismissal Legislation in the United States," Industrial and Labor Relations Review, 44(4), 644-660.

Mailath, G. J., and L. Samuelson (2001): "Who wants a good reputation," Review of Economic Studies, 68, 415-441.

Nagin, D. S., J. B. Rebitzer, S. Sanders, and L. J. Taylor (2002): "Monitoring, Motivation and Management: The Determinants of Opportunistic Behavior in a Field Experiment," American Economic Review, $92(4), 850-873$.

Polinsky, M., And S. Shavell (2000): "The Economic Theory of Enforcement of Law," Journal of Economic Literature, 38(1), 45-76.

Sadanand, A., V. Sadanand, and D. Marks (1989): "Probationary contracts in agencies with bilateral asymmetric information," Canadian Journal of Economics, 22(3), 643-661. 
Wang, R., and A. Weiss (1998): "Probation, layoffs, and wage-tenure profiles: A sorting explanation," Labour Economics, 5(3), 359-383. 